\title{
Analyzing Growth Patterns of Greater Kumasi Metropolitan Area Using GIS and Multiple Regression Techniques
}

\author{
Charles Yaw Oduro ${ }^{1}$, Kafui Ocloo ${ }^{1} \&$ Charles Peprah $^{1}$ \\ ${ }^{1}$ Department of Planning, Kwame Nkrumah University of Science \& Technology, Kumasi, Ghana \\ Correspondence: Charles Yaw Oduro, Department of Planning, Kwame Nkrumah University of Science \& \\ Technology, University Post Office, KNUST, Kumasi, Ghana. Tel: 233-201-376-089. E-mail: \\ yawoduro68@gmail.com
}

Received: February 21, 2014 Accepted: March 11, 2014 Online Published: September 14, 2014

doi:10.5539/jsd.v7n5p13 URL: http://dx.doi.org/10.5539/jsd.v7n5p13

\begin{abstract}
Currently, half of the world's population lives in urban areas and the tempo of urbanization is expected to continue unabated during the $21^{\text {st }}$ century, with most of the growth occurring in the developing world. The metropolitanization of African urban centres has brought in its wake several challenges, including uncontrolled physical development, inadequate and deteriorating infrastructure, and traffic congestion. To address the challenges, there is the need to understand the patterns of growth and structure of these urban centres. However, little work has been done in this regard. In this paper, we sought to model the patterns of growth of the Greater Kumasi Metropolitan Area (GKMA) in Ghana. Using GIS and multiple-regression techniques, we have demonstrated that the form and growth of GKMA follow discernible patterns that can be explained by the monocentric city model and the ribbon development pattern of spatial growth. There are non-linear, negative relationships between distance from Central Kumasi and distance from highways (as predictors) and the dependent variables population density and population growth. The findings indicate that Africa's metropolitan areas follow discernible patterns that can be explained by existing models applied in other regions.
\end{abstract}

Keywords: Ghana, Greater Kumasi Metropolitan Area, monocentric, growth pattern, ribbon development

\section{Introduction}

Over half of the world's population lives in urban areas and the tempo of urbanization is expected to continue unabated during the $21^{\text {st }}$ century, with most of the growth occurring in developing countries (UN-Habitat, 2008; United Nations [UN], 2012; World Bank, 2000). The urbanization process involves the coalescing of cities and towns to form complex urban systems and rapid engulfment of peri-urban farmlands (UN-Habitat, 2008). Since these urban systems serve as the engines of growth of national and regional economies (UN-Habitat, 2008; UN, 2012), urbanization is often thought to be associated with high levels of socio-economic development and wellbeing, albeit the myriad urban problems found in many countries (Bairoch, 1988; Bertinelli \& Black, 2004; Moomaw, 1996; Oduro, 2010).

Ghana has had its share of urban population explosion in the last six decades. In 1948, 13\% of the country's population lived in 39 urban centres but, by 2000 , about $44 \%$ of the population lived in 364 urban centres (see Oduro, 2010). According to the 2010 Population and Housing Census, over half of the country's population now resides in urban centres (Ghana Statistical Service [GSS], 2012). Ghana's urbanization has resulted in the rapid growth of its major cities, particularly Accra, the national capital, and Kumasi, the capital of the Ashanti Region. Census data show that Kumasi's population, which stood at 2035064 as of 2010, registered and maintained a remarkable growth rate of over 5\% per annum between 1984 and 2010, making it the fastest growing major city in Ghana. This has resulted in the expansion of the built-up area, conversion of farmlands to urban uses and intensive spatial interactions between the city and surrounding settlements (Aberra \& King, 2005; Afrane \& Amoako, 2011; Cobbinah \& Amaoko, 2012; Simon, McGregor \& Nsiah-Gyabaah, 2004).

Having evolved from a pre-colonial township, the city of Kumasi has now become the nucleus of an emerging metropolitan region (thereafter referred to as Greater Kumasi Metropolitan Area or GKMA) that comprises the old city and six adjoining districts-Ejisu-Juabeng, Bosomtwe, Kwabre East, Afigya Kwabre, Atwima Nwabiagya and Atwima Kwanwoma (see Figure 1). The GKMA covers an area of approximately 2746 square kilometres and had a combined population of 2564120 in 2010, 79\% of which resided in the Kumasi metropolis 
itself. Many settlements in the adjoining districts accommodate both indigenous populations and migrant residents who use those settlements as dormitory towns - peri-urban settlements where residents spend the night and commute to work in the city.

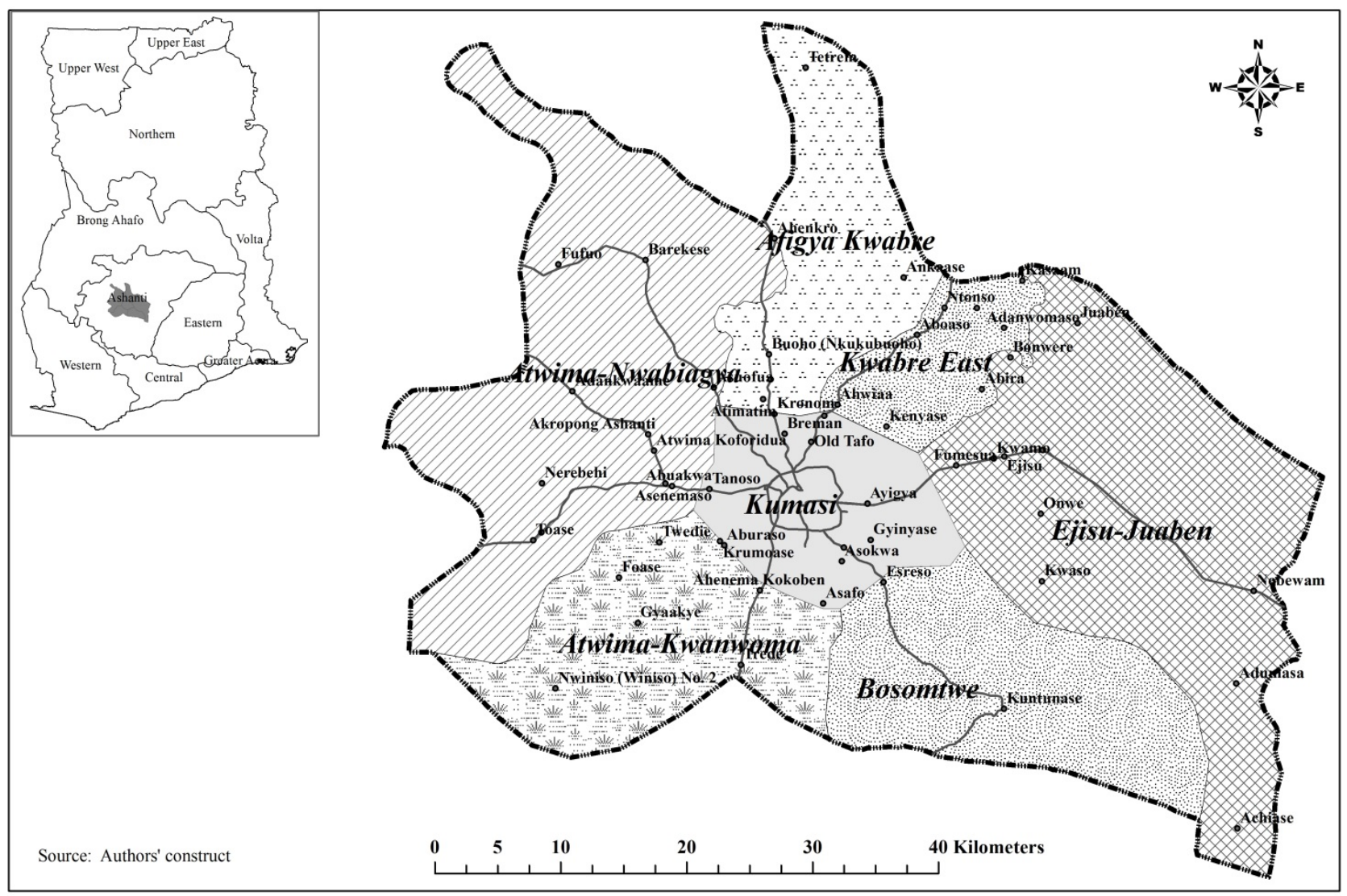

Figure 1: Greater Kumasi Metropolitan Area in National and Regional Context

The metropolitanization of African urban centres has brought in its wake several challenges, including uncontrolled physical development, inadequate and deteriorating infrastructure, traffic congestion, environmental degradation, acute housing shortage, among others (Chirisa, 2008). One step towards addressing these challenges is to understand the nature and pattern of growth of African urban centres and the urban spatial structure and form they produce. However, little work has been done in this regard. Some scholars have variously depicted the African city as informal, amorphous, formless and a footprint of urban poverty (e.g. Davis, 2006; Mabogunje, 1990). For example, Mabogunje describes it as "a human agglomeration with no clear set of criteria to help its identification as a socially distinct entity" (Mabogunje, 1990: 121). Others view the African city as not conforming to existing notions of growth and development, reflecting the "African love affair with the hodgepodge" (Simone, 2004: 2). However, other scholars suggest that the African city has a discernible growth pattern that can be explained by various urban growth models (e.g. Doan \& Oduro, 2012; Potter \& Lloyd-Evans, 1998; Vermeiren, Van Rompaey, Loopmans, Serwajja \& Mukwaya, 2012). Unfortunately, most of these notions of the African city are not based on rigorous empirical analysis of the continent's urban form and growth patterns. To contribute to the filling of this gap, we sought to analyse the patterns of population growth and physical expansion of the GKMA and the forces that have created these patterns.

\section{Theoretical Underpinnings}

Cities are formed through the agglomeration of human populations, activities and infrastructure at particular locations, such as seaports and road intersections. One reason for this is that agglomeration produces external economies of scale that stimulate socio-economic growth (Alonso-Villar, 2001; Glaeser, 1999; Handerson, 2002; 2004; Krugman, 1991). Urban agglomeration also interacts with factors such as local ecological conditions, landscape, types and distribution of land uses, and mobility to produce the spatial structure and growth patterns of cities and metropolitan areas. Over the decades, several models have been developed to explain and generalize 
the nature of urban spatial structure and patterns. Two of these models-monocentric city model and ribbon development- - form the theoretical underpinnings of this paper.

\subsection{The Monocentric City Model}

The monocentric city model was developed in the 1960s and 1970s based on William Alonso's (1964) bid rent model and similar works by Edwin Mills and Richard Muth (Kraus, 2003) as well as Clark's (1951) urban population density gradient model. The logic of the monocentric city model can be traced to J.H. von Thünen's land use model, which is premised on the existence of a flat and isolated state and a uniform mode of transportation, and seeks to predict a concentric land use pattern centred on a central city (market) (see Dickinson, 1969). Similarly, the monocentric city model is premised on the existence of a centrally-located, economically-dominant central business district (CBD) that influences the land use pattern of a city. The model suggests that the value (rent) of land and housing, population density and structural density decrease with distance from the CBD while household income and housing consumption increase with distance from the CBD (Brueckner, 1987; Kraus, 2003; McMillen, 2006; Romein, Verkoren \& Fernandez-Maldonado, 2009). Having the highest concentration of retail and other non-agricultural economic activities, and being the most accessible point in the urban area, land at the CBD attracts the highest demand and the highest rent (Alonso, 1964; Trussell, 2010). As one moves away from the CBD, both the attractiveness and rent of land decline.

Another feature of the monocentric city model is the prediction of the variation in population density across the metropolitan area relative to the CBD. That is, as Clark (1951) proposed decades earlier, the relationship between urban population density and distance from the CBD depicts a negative gradient (see McMillen, 2006). This is because developers respond to the relatively high land rent in and around the CBD by building homes with high capital-land ratios which in turn leads to high population densities at the city centre. The opposite happens at locations farther away from the CBD. This population density gradient has been found to apply to Nairobi, Kenya, (see Kahimbaara, 1986) while population increase is found to be one of the major forces shaping the spatial structure of the city of Ile-Ife, Nigeria (Ajala1 \& Olayiwola, 2013). However, McMillen (2006) notes that declining commuting cost has the tendency to flatten the slope of the gradient over time.

The monocentric city model also suggests that the intensity of physical development (structural density) decreases with distance from the CBD (McMillen, 2006). This is directly linked to the land rent and population density gradients. To offset the high land rents in and around the CBD, property developers maximize the use of land by building structures (homes, offices, etc.) with high capital-land ratios. Secondly, to accommodate the high concentrations of population in and around the $\mathrm{CBD}$, it is only natural that physical residential development would be most intensive in such areas. Additionally, the development of physical infrastructure (particularly roads) that supports commercial and residential activities would be most intensive in and around the CBD. Moreover, as Linard, Tatem and Gilbert (2013) found, one of the forces that drive urban expansion (i.e. growth of the built-up area) is accessibility to the CBD. Since accessibility (measured in terms of travel time) is influenced by distance, urban expansion should be expected to be more intensive in areas that are close to the $\mathrm{CBD}$ than areas that are farther away, ceteris paribus.

One of the shortcomings of the monocentric city model is that the existence of a single dominant CBD containing most jobs may not entirely apply to some of today's metropolitan areas. For example, since the twentieth century, metropolitan areas in Europe and North America have been characterized by the dispersion of population and economic activities from central cities to the suburbs (Anderson, Kanaroglou \& Miller, 1996). As Boshoff and Marais (2013) have observed, rather than being concentrated at one location, "activity districts" in modern cities tend to be dispersed. In the case of Tshwane, South Africa, "the future of its CBD is heading on a downward spiral as Tshwane's economic output is spreading across the entire city" (Boshoff \& Marais, 2013: 18). To incorporate this reality, the polycentric city model has been proposed as an alternative to the monocentric model. The polycentric model recognises the fact that, in addition to the possibility of a dominant $\mathrm{CBD}$, the modern metropolitan area has several sub-centres that compete with the main CBD for population and economic activities (Anas, Arnott \& Small, 1998; Anderson et al., 1996; Kraus, 2003; Romein et al. 2009). This model is similar to the Harris-Ullman model (a.k.a. multiple-nuclei model), which acknowledges that a city will have a single CBD at its early stages but, over time, specialized industrial and commercial districts are established at other locations (see Hall, 1997; Torrens, 2000).

In addition, distance from the CBD cannot be solely responsible for variations in land and housing values as other factors play a significant role. For example, in the city of Onitsha, Nigeria, non-locational factors such as time of land purchase explain more of the variation in residential land value than distance from CBD (Uju \& Iyanda, 2012). Factors such as age of neighbourhood, infrastructure and structural attributes have also been 
identified as major determinants of land and housing values (Olaore, 1991; Megbolugbe, 1983; Arimah, 1990 all cited in Uju \& Iyanda, 2012).

Despite their inherent weaknesses, some scholars maintain that the predictions of the monocentric city model are still relevant in explaining spatial patterns in today's metropolitan areas. For example, after reviewing some of the empirical works on the monocentric city model, McMillen (2006) came to the conclusion that the model is still relevant, arguing that the central city continues to dominate urban spatial patterns. He also observed that, even in metropolitan areas where the polycentric pattern has been observed, the basic ideas underlying the monocentric city model are applicable in explaining the influence of multiple centres. In Eugene, Oregon, Trussell (2010) used econometric analysis to establish a "statistically significant relationship" between housing rent and distance from the $\mathrm{CBD}$, after controlling for income, topography and cardinal direction.

\subsection{Ribbon Development}

Another model that seeks to explain and generalize the nature of urban spatial structure is the ribbon development pattern. This model addresses the effects of road networks on urban spatial structure (see Chin, 2002; Doan \& Oduro, 2012; Harvey \& Clark, 1965). Progress in transportation technology and use of private automobiles has made it possible for urban residents to commute over long distances to the CBD and the suburbs. Thus, ribbon development describes a kind of urban development "composed of segments compact within themselves but which extend axially and leave the interstices undeveloped" (Harvey \& Clark, 1965, p. 2). In order to have the circular shape and the radially uniform pattern of growth implied by the monocentric city model, the radial arms of the road network that connects the city centre with other parts of the metropolitan area "must be sufficiently dense that circumferential access costs can safely be ignored" (Kraus, 2003, p. 20). However, in reality, radial roads are often discretely spaced and circumferential access tends to be costly. This usually leads to urban growth that follows major arterial roads and in which the boundary between the urban and rural landscapes is non-circular (Anas \& Moses, 1979 cited in Kraus, 2003). One reason for this phenomenon is the fact that demographic and physical growth in urban areas is influenced by accessibility to the city centre (Linard, Tatem \& Gilbert, 2013). In metropolitan areas like GKMA where both radial and circumferential roads are few, accessibility (travel time) to the city centre is influenced by commuters' ability to use the few highways connecting the city centre to the outskirts. Consequently, physical and demographic growth, as well as population density, is more intensive in areas that are close to highways than areas that are farther away from highways, ceteris paribus.

\section{Hypotheses about the Growth Patterns of GKMA}

The focus of this paper is to model the spatial patterns of the growth of GKMA. Spatial patterns of growth here refer to spatial variation in population density, population growth and the urbanized (built-up) area, as well as changes in these parameters over time. Based on insights from the preceding theoretical discourse, we hypothesise that Central Kumasi and the major highways that traverse the metropolitan area drive and direct the spatial patterns of growth of GKMA. 


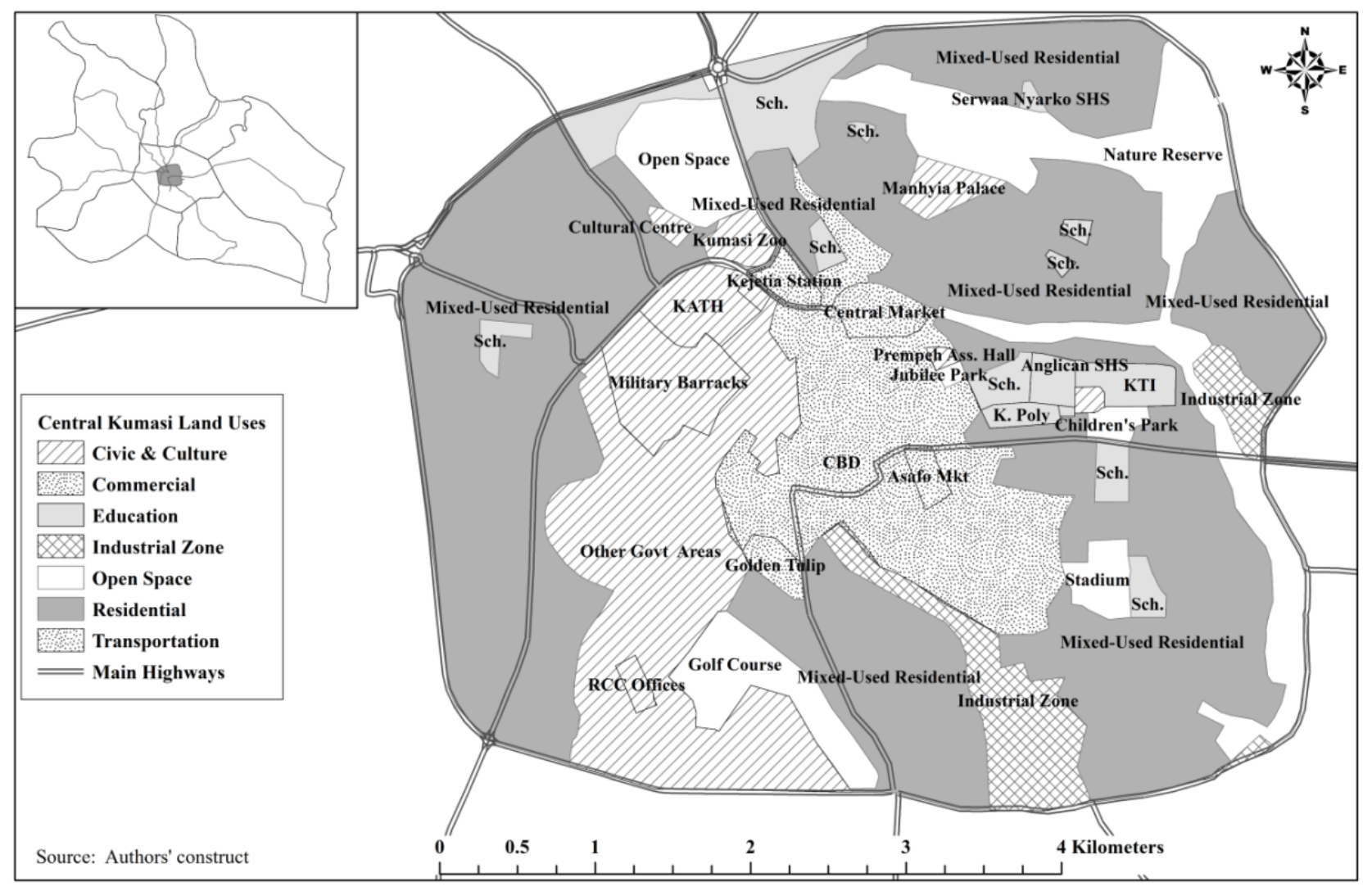

Figure 2. Land use characteristics of central Kumasi

In this paper, Central Kumasi refers to the core of the city of Kumasi and is delineated as the area enclosed by the city's ring road (see Figure 2). It is the commercial and administrative hub of the city, containing the offices of many public institutions; the main CBD (which includes several financial institutions, the Adum shopping area, Asafo Market and the Kumasi Central Market, one of the largest markets in Ghana); the Kejetia transport terminal; the Komfo Anokye Teaching Hospital (KATH) and numerous other health institutions; several primary, secondary and tertiary educational institutions; the Baba Yara Sports Stadium; the Kumasi Zoo; and Kumasi Cultural Centre. Central Kumasi also consists of several old communities, notable among which are Bantama, Adum, Aboabo, Asawase, Ashanti Newtown, Asafo, Amakom and Manhyia. Manhyia is the seat of the Asantehene, the overlord of the erstwhile Ashanti kingdom.

Central Kumasi serves as the most important employment centre in the GKMA. This results in the generation of large volumes of commuter trips between the centre and other communities across the metropolitan area. In addition, the numerous high-order facilities and institutions located within Central Kumasi, together with nearby facilities like the Kwame Nkrumah University of Science and Technology (KNUST) and the Suame Industrial Estate (Mgazine), make Kumasi an important service centre with a sphere of influence that goes beyond the Ashanti Region. Given its commercial, administrative, historical and cultural significance, Central Kumasi is undoubtedly the nucleus around which the rest of the city has evolved over the decades. It is also a major part of what makes Kumasi attract migrant and commuter population from the rest of the GKMA, the Ashanti Region and beyond. In view of the dominant role of Central Kumasi, and the absence of major competing sub-centres, we propose that the GKMA exhibits a monocentric pattern. (Although communities such as Ejisu, Ayigya, Kwadaso and Ahinsan within the GKMA have markets that are quite vibrant, their influence on the space economy of GKMA is eclipsed by Central Kumasi.) Therefore, we hypothesize that the population and physical growth of the metropolitan area follow a concentric pattern with Central Kumasi acting as the nucleus. 


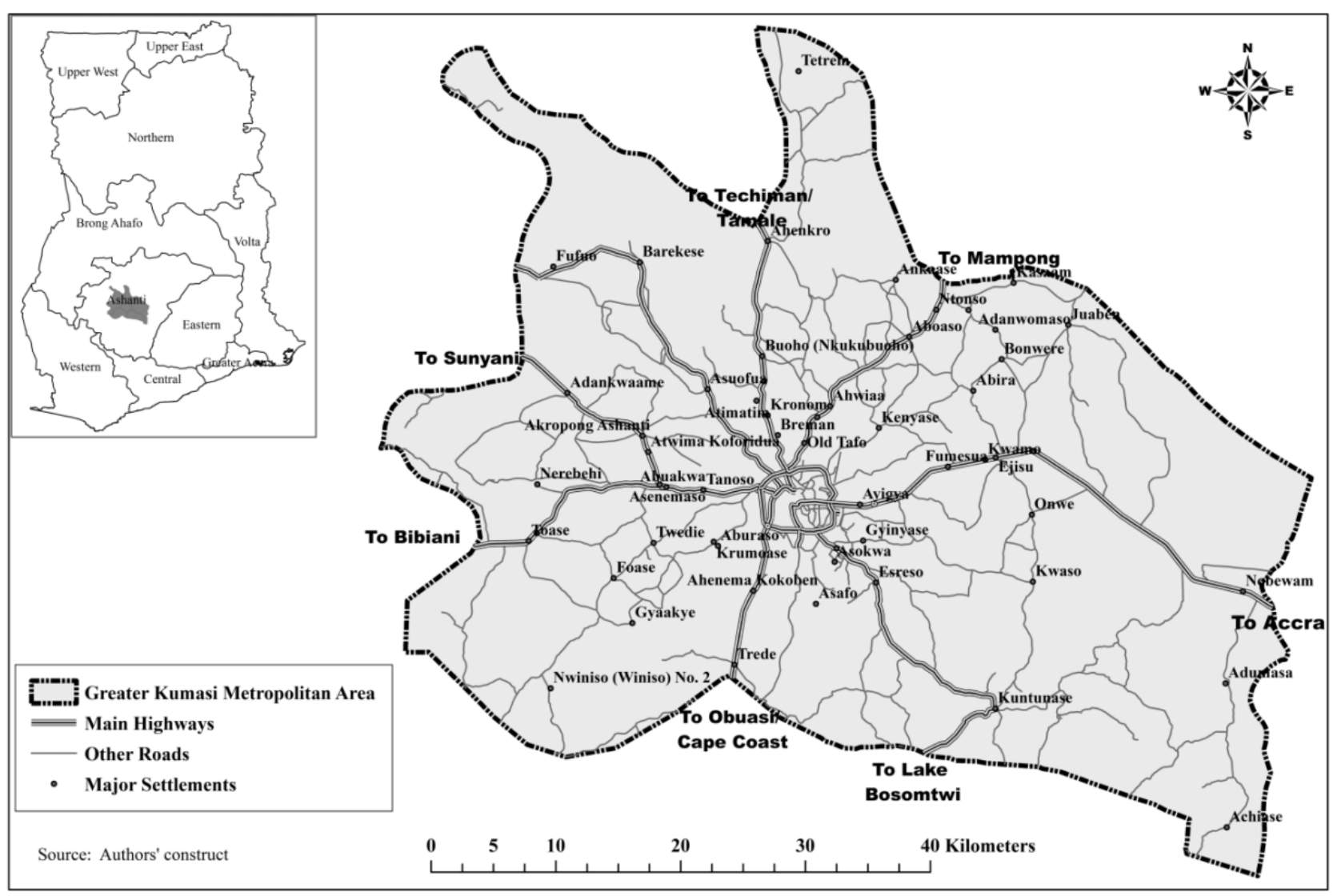

Figure 3. Main highways and other roads in Greater Kumasi Metropolitan Area

Kumasi is also a nodal city where about seven (7) major highways converge. They are the Kumasi-Accra, Kumasi-Mampong, Kumasi-Techiman, Kumasi-Barekese, Kumasi-Bibiani, Kumasi-Obuasi/Cape Coast and Kumasi-Lake Bosomtwe highways (see Figure 3). Besides connecting Kumasi and the GKMA to other parts of the country, these highways provide commuters with easy access to the city centre. This means that living close to these highways enhances residents' ability to commute to the city centre. We therefore hypothesize that highways traversing the GKMA attract population and that population density and population growth are highest along the corridors of the highways and decrease with distance from the highways. Since population growth leads to physical growth, we further hypothesize that the expansion of the contiguously built-up area, which originated from Central Kumasi, follows the highways and into the surrounding municipalities. In other words, in addition to its monocentric character, the demographic and physical growth of GKMA is expected to exhibit a ribbon development pattern.

\section{Methods}

We applied GIS and multiple regression techniques to model the spatial patterns of growth of GKMA in terms of population density, population growth and the built-up area. We constructed a digital basemap of GKMA using maps and other spatial data obtained from the Physical Planning Department of Kumasi Metropolitan Assembly, the six adjoining district/municipal assemblies, the Ghana Survey Department, OpenStreetMap and Google Earth. The resultant basemap included features such as the boundaries of Kumasi Metropolis and the six adjoining districts/municipalities, names and locations of settlements, the road network, land uses in Central Kumasi, and the built-up area of GKMA as of 1972 and 2012. (The choice of these and other years was influenced by the availability of relevant spatial and population data.)

The demographic aspects of the analysis were based on settlement populations in 1970, 1984, 2000 and 2010, which were obtained from censuses conducted in those years by the Ghana Statistical Service (GSS). While population figures in 1970, 1984 and 2000 were available at the settlement (locality) level, those in 2010 were only available at district, municipal, sub-metropolitan and metropolitan levels. To obtain the 2010 population figures for settlements, the respective district, municipal and sub-metropolitan populations were prorated based 
on the ratios of the populations of individual settlements in each district, municipality or sub-metropolitan council area in 2000. The compiled settlement population database (for 1970, 1984, 2000 and 2010) was then digitally joined to the spatial (GIS) database of settlements contained in the base map. In all, the study covered 406 settlements for which both spatial (GIS) and population data were available; they account for over $95 \%$ of the total population of the GKMA.

ArcGIS was used to create a series of concentric rings around Central Kumasi, with each ring measuring two (2) kilometres in width. The area covered by each ring and the corresponding aggregate population figures of each ring (based on a summation of the populations of settlements located in that ring) were then digitally estimated, making it possible to calculate and map the population density of each concentric ring. The same method was used to compute and map population densities for 2-kilometre-wide strips constructed and arranged successively on both sides of each of the main highways in the GKMA. The generated data also made it possible to graph population density gradients over distance from Central Kumasi and distance from highways. Population growth between 1970 and 2010 in each concentric ring and each strip was also calculated and mapped using the dot-mapping technique. Finally, multiple regression techniques were used to construct statistical models of settlement population growth over different censal periods. In this part of the analysis, settlements were used as the units of observation while distance from Central Kumasi and distance from the nearest highway were treated as independent variables predicting the dependent variable, population growth.

\section{Results}

\subsection{Growth Pattern of the Built-Up Area}

The total built-up area of GKMA almost quintupled from approximately 98 square kilometres in 1972 to approximately 478 square kilometres in 2012 - an arithmetic growth rate of 9.5 square kilometres per annum. The growth involved the expansion of the contiguously built-up area of the city itself, as well as the built-up areas of peri-urban and previously rural communities (see Figure 4). The contiguously built-up area more than quintupled from 74.4 square kilometres (or $75.9 \%$ of the total built-up area of GKMA) in 1972 to 421.2 square kilometres (or $88.1 \%$ of total built-up area) in 2012 .

The growth of the built-up area involves the natural expansion of the contiguously built-up area of Kumasi to accommodate the city's growing population and non-agricultural activities. It also involves a merger between the built-up area of the city and those of nearby peri-urban communities. The combined effect of these two processes is that the contiguously built-up area has now expanded well beyond the administrative boundaries of the Kumasi Metropolis. In 1972, only 3.6\% of the contiguously built-up area was outside the Kumasi Metropolis but this had increased to $46.4 \%$ by 2012 (see Figure 4). Thus, to a large extent, the growth of the built-up area of GKMA has been influenced by proximity to the central city, Kumasi. 


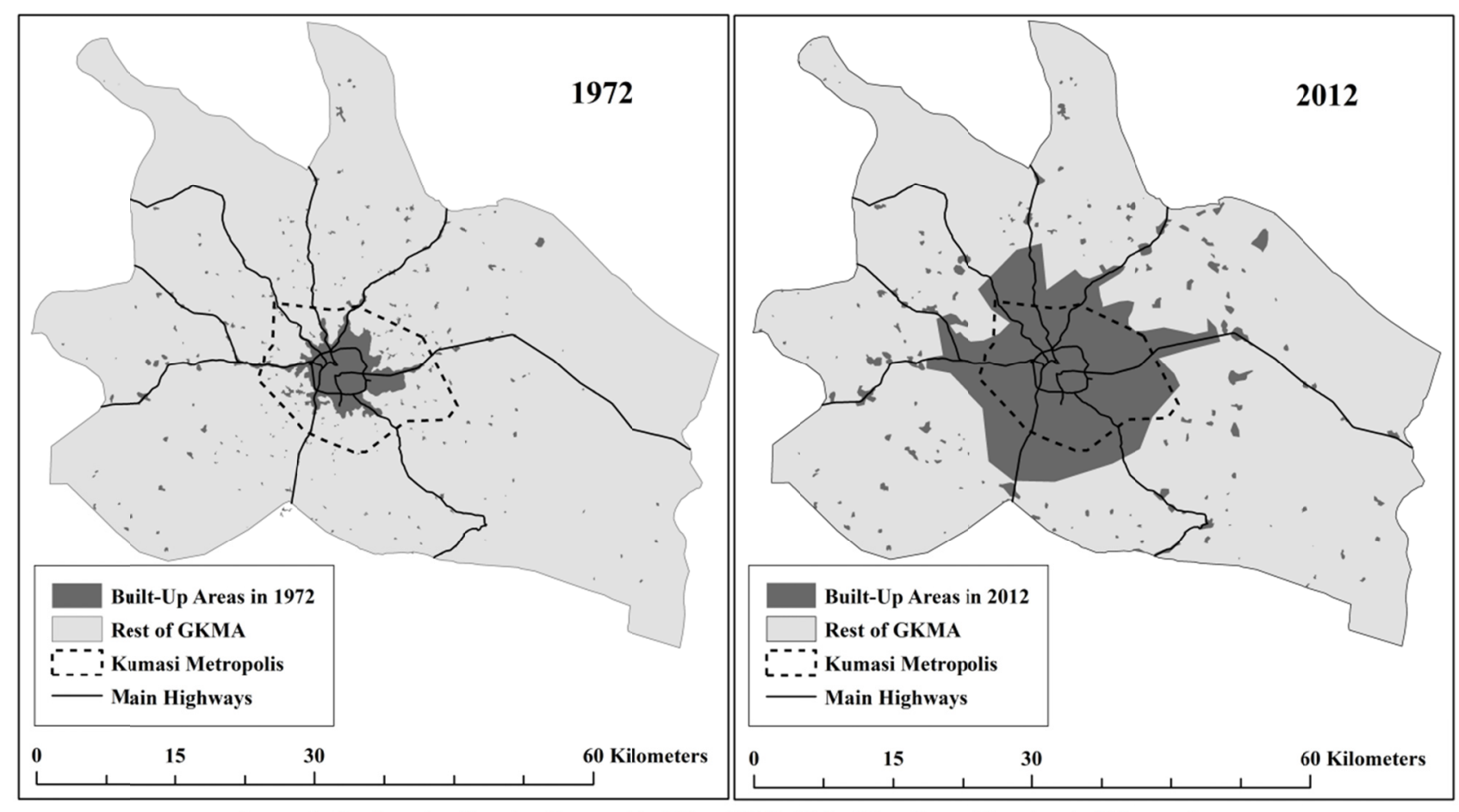

Source: Authors' construct based on Topographical Maps (1972) obtained from Survey Department of Ghana and spatial data (2012) extracted from OpenStreetMap

Figure 4. Built-up areas of Greater Kumasi Metropolitan Area in 1972 \& 2012

Moreover, a close examination of Figure 4 reveals that, besides proximity to Kumasi, the road network has had a significant influence on the growth pattern of the built-up area.

The analysis also shows that the population of GKMA grew faster than its built-up area. While the total population increased by $484 \%$ between 1970 and 2010, the total built-up area increased by approximately $388 \%$ during the period. The fast growth of GKMA's population relative to its built-up area is also manifest in the fact that about $84 \%$ of the population increase between 1970 and 2010 was concentrated in the Kumasi Metropolis itself, compared to the Greater Accra Metropolitan Area (GAMA) where most of the recent increases in population have occurred outside the Accra Metropolis (see Oduro, 2010). 
5.2 Effect of Central Kumasi on Spatial Patterns of Population Density and Growth (1970-2010)

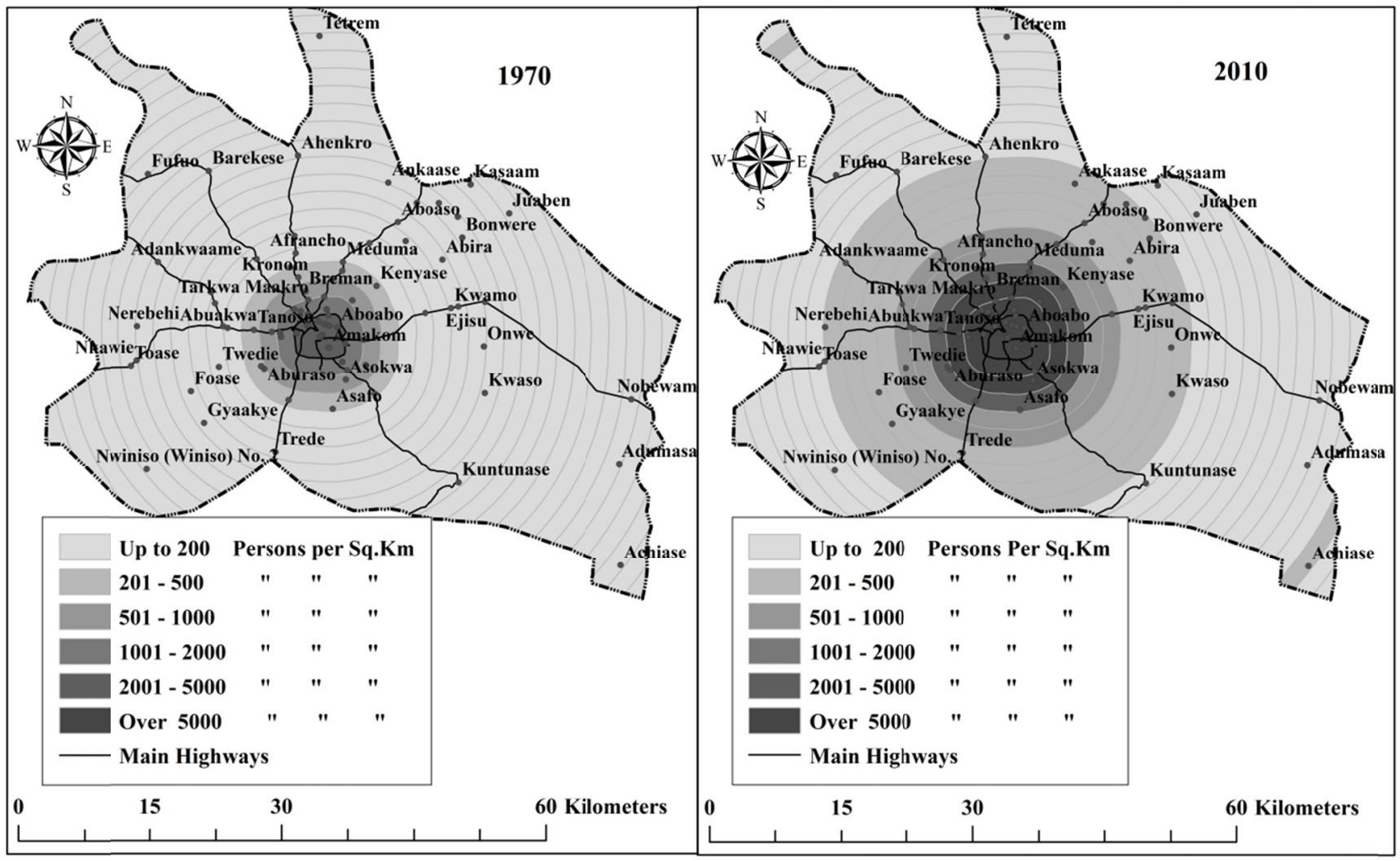

Source: Authors' construct based on 1970 and 2010 Population Censuses conducted by Ghana Statistical Service (GSS)

Figure 5. Population density by proximity to central Kumasi in $1970 \& 2010$

Results of the spatial modelling reveal that, between 1970 and 2010, population density in the GKMA (measured as number of persons per square kilometre) was highest in Central Kumasi and decreased with distance from Central Kumasi (see Figure 5). For example, in 1970 average population density peaked in Central Kumasi at 4,518 persons per square kilometre but decreased drastically to 1,042 persons per square kilometre at locations within a range of only 2 kilometres from Central Kumasi and a low of 11 persons per square kilometre at locations 26-28 kilometres away. A similar pattern was observed in 1984, 2000 and 2010. 


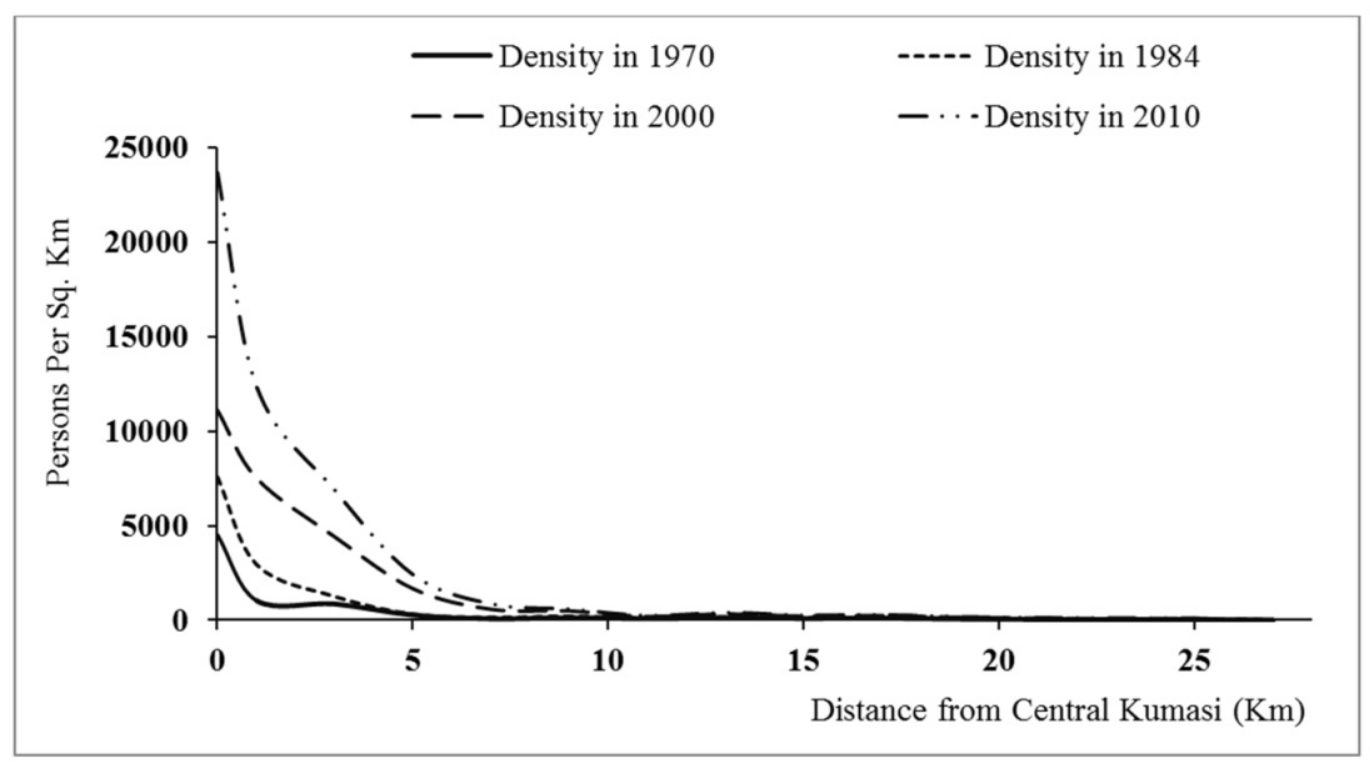

Figure 6. Population density gradients by proximity to central Kumasi in 1970, 1984, $2000 \& 2010$

The effect of proximity to Central Kumasi on the spatial patterns of population density in the GKMA is further illustrated by population density gradients for 1970, 1984, 2000 and 2010 (see Figure 6). Although population density increased throughout the metropolitan area during the period, the density gradient remained negative in all the four years. Figure 6 also shows that the population density curve for the study area was non-linear in all the four years. For example, the 2010 curve begins with a high value of 23658 persons per square kilometre at the point where the distance value is zero (which represents Central Kumasi), declines sharply over the first 5 kilometres, slows down for roughly another 5 kilometres and flattens out as distance from Central Kumasi increases. In other words, population density does not only decrease with distance from Central Kumasi but does so at a decreasing rate.

Besides population density, the data has shown that Central Kumasi had tremendous effect on the spatial patterns of population growth between 1970 and 2010. Generally, population growth was faster in and around Central Kumasi than areas farther away.

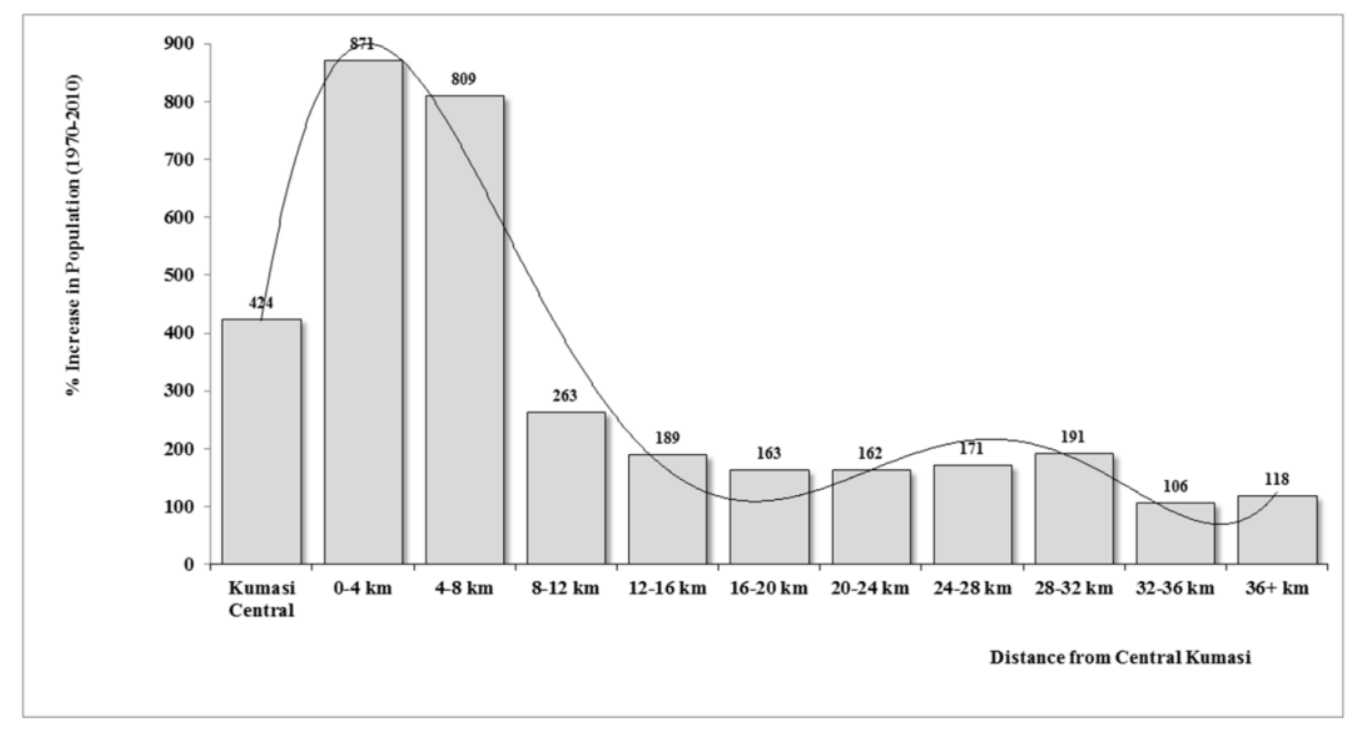

Figure 7. Percentage increase in population by proximity to central Kumasi, 1970-2010

However, unlike the density gradient, the population growth curve is not a near-hyperbola; rather, it 
approximates a five-order polynomial (see Figure 7). As Figure 7 shows, although Central Kumasi registered a remarkably high average growth of $424 \%$ during the 40 -year period, this was less than half of the average of $871 \%$ registered by areas located outside Central Kumasi but within 4 kilometres away. The growth in areas located within 4-8 kilometres from Central Kumasi (809\%) was similarly high. However, there was a sharp drop in density in areas located beyond 8 kilometres from Central Kumasi where growth fluctuated between $106 \%$ and $263 \%$. In fact, further analysis shows that the Central Kumasi accounted for $22 \%$ of the total increase in population in the GKMA, areas located within 0-8 kilometres from Central Kumasi accounted for $63 \%$ while the rest of the metropolitan area accounted for the remaining $15 \%$.

\subsection{Effect of Highways on Spatial Patterns of Population Density and Growth (1970-2010)}

The study shows that, apart from Central Kumasi, the road network has tremendous influence on the spatial pattern of population density.

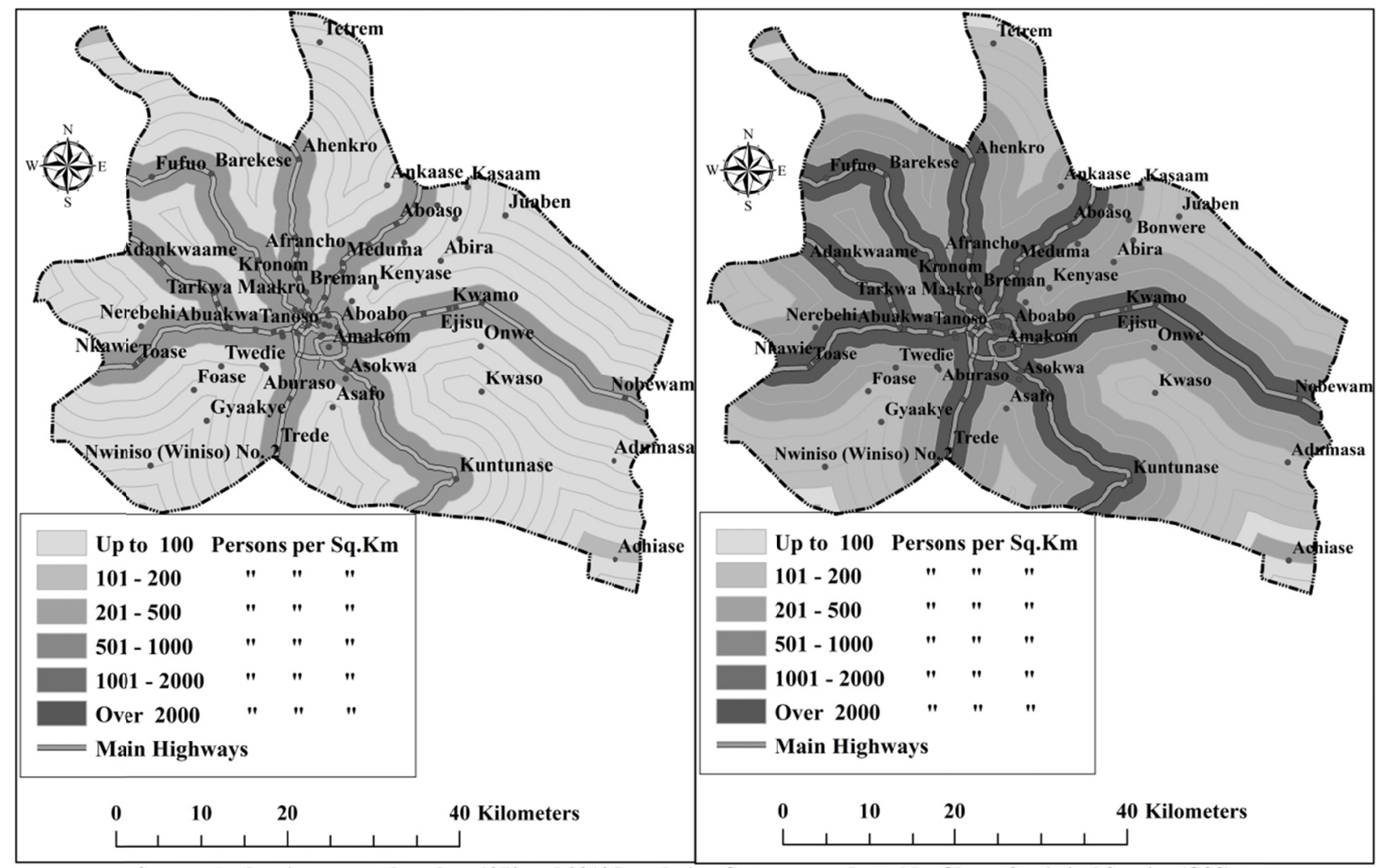

Source: Authors' construct based on 1970 and 2010 Population Censuses conducted by Ghana Statistical Service (GSS)

Figure 8 . Population density by proximity to highways, 1970 and 2010

As Figure 8 shows, in both 1970 and 2010, population density was highest in areas within 2 kilometres of a highway and declined significantly with distance from highways. For example, in 2010, average population density was as high as 2653 persons per square kilometre in areas within 2 kilometres of a highway and as low as 74 persons per square kilometre in areas between 14-16 kilometres from a highway. 


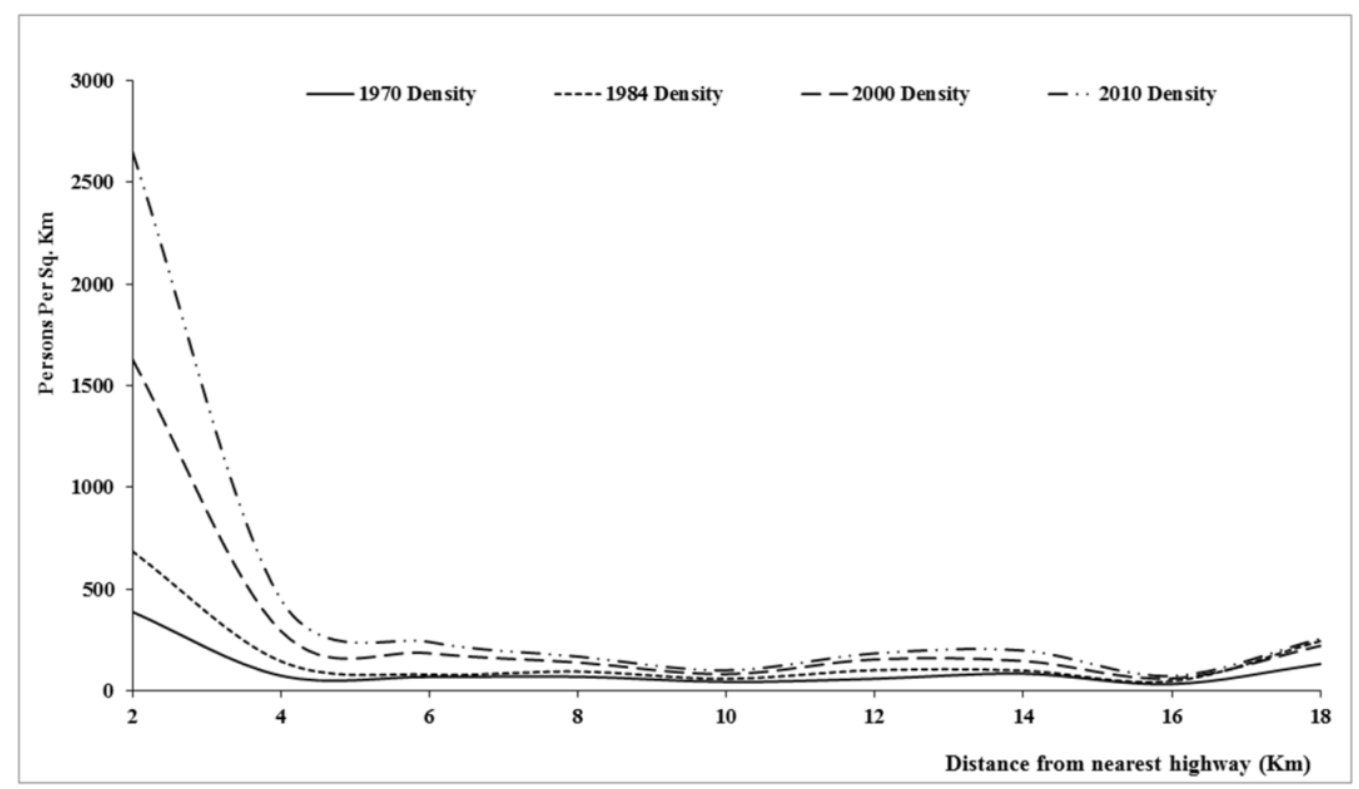

Figure 9. Population density gradient by proximity to highways in 1970, 1984, 2000 and 2010

As the graph in Figure 9 illustrates, this negative relationship between population density and distance from highway was non-linear in all the four reference years-1970, 1984, 2000 and 2010. In all four cases, the density curve begins with a high value when distance is 2 kilometres, slopes sharply for another 2-3 kilometres and thereafter approaches the distance-axis asymptotically. However, as far as the data and timeframe used for the analysis are concerned, this spatial pattern of population density distribution holds true for areas within approximately 10 kilometres of a highway; areas beyond 10 kilometres do not show any discernible pattern.

Highways have also had tremendous effects on the spatial pattern of population growth in the GKMA. The analysis shows that areas close to highways have experienced a much faster growth in population than areas that are farther away.

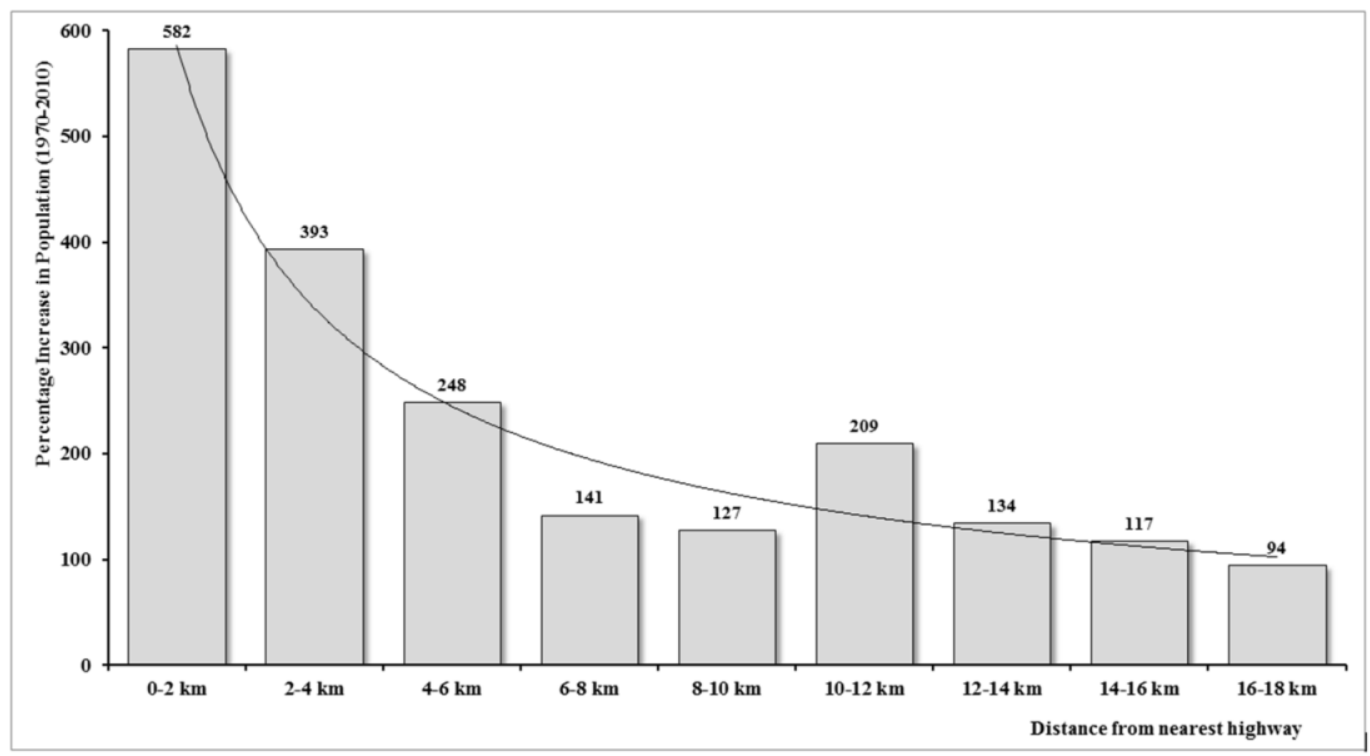

Figure 10. Percentage increase in population by proximity to highways, 1970-2010

As illustrated in Figure 10, between 1970 and 2010, areas within 0-2 kilometres from a highway registered the 
largest population increase of $582 \%$. This was followed by areas 2-4 kilometres from a highway where population increased by $393 \%$. All areas farther than 16 kilometres from a highway registered less than $100 \%$ increase in population during the same period. Indeed, areas within 0-4 kilometres from a highway accounted for about 93\% of population increase in the entire GKMA during the 40-year period (i.e. 1970-2010). This pattern depicts a non-linear, negative relationship between population growth and distance from highways.

\subsection{Combined Effect of Central Kumasi and Highways}

The results presented so far show that both Central Kumasi and the highway network, standing alone, influence the spatial patterns of population density, population growth and spread of the built-up area.

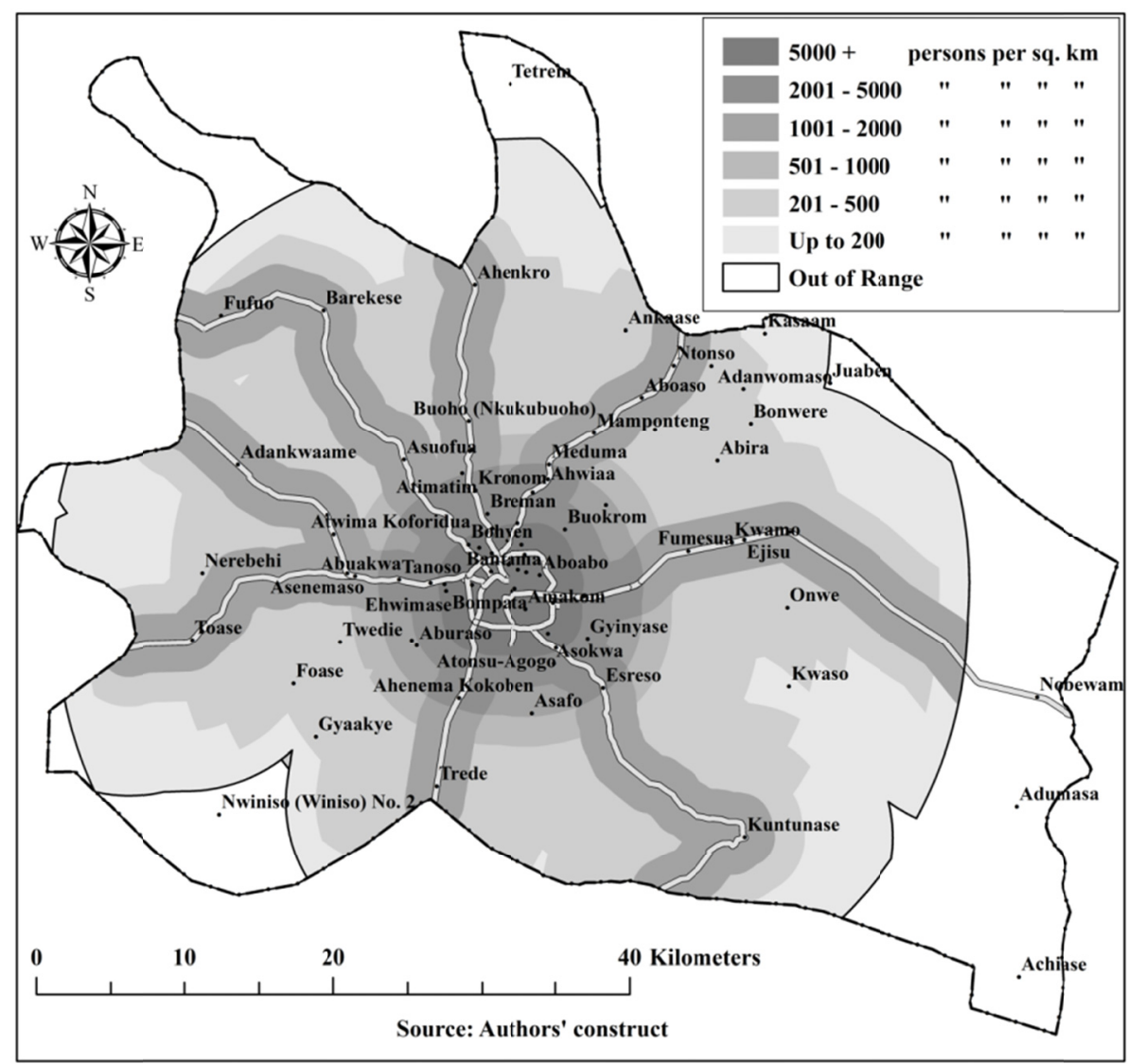

Figure 11. Population density by proximity to central Kumasi \& Highways in 2010 


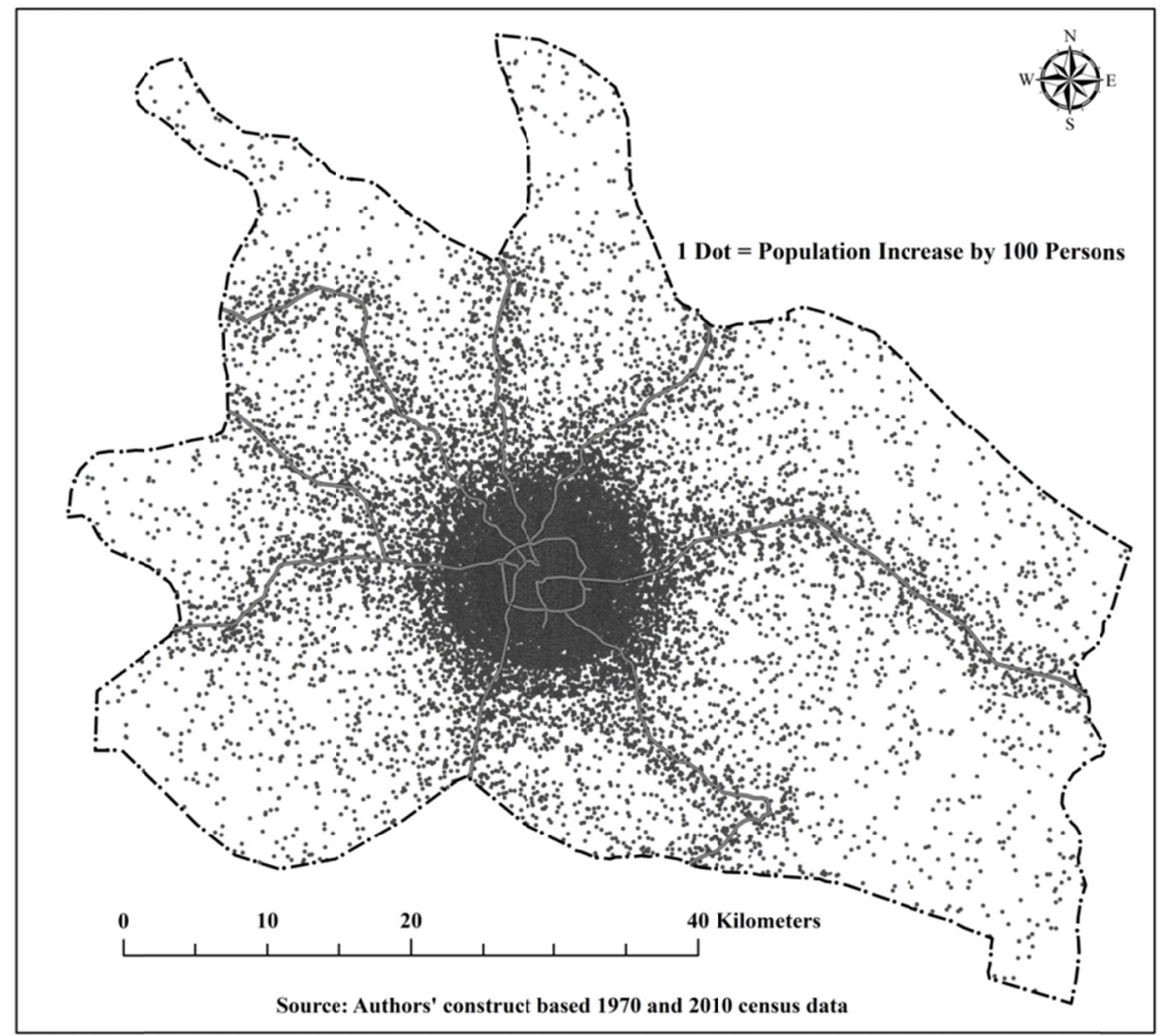

Figure 12. Absolute population growth by proximity to central Kumasi \& Highways, 1970-2010

Figures 11 and 12 are GIS-generated models that depict the combined effects of Central Kumasi and the highway network on the spatial patterns of population density in 2010 and absolute population growth during the period 1970-2010, respectively. Both spatial models show that, to a large extent, GKMA is primarily monocentric with Central Kumasi as its nucleus. However, this monocentric tendency is significantly distorted by a ribbon development pattern driven by the main highways.

\subsection{Statistical Modelling of Population Growth Patterns}

The combined effects of Central Kumasi and highways on the spatial pattern of population growth in the GKMA as depicted by GIS modelling have been statistically confirmed in this study. Using the 406 settlements covered in the study as units of observation, a multiple regression analysis was applied to model the effects of proximity to Central Kumasi and highways on absolute population growth. Thus absolute population growth $(\mathrm{G})$ during a given period was treated as the dependent variable while distance from Central Kumasi (C) and distance from nearest highway $(\mathrm{H})$ were treated as the main independent variables. Examination of the data revealed that $\mathrm{C}$ and $\mathrm{H}$ were not normally distributed as assumed by the ordinary least square (OLS) method and this problem was resolved by transforming the two variables into square root and log, respectively. Also, the size of a settlement's population in the base year of the period over which population growth was modelled was included as an additional independent variable. This was necessary to control for the fact that the absolute growth in the population, to some degree, is dependent on initial population size (i.e. base year population). Thus, various models were used to predict $\mathrm{G}$ based on the following independent variables:

$\sqrt{ } C=$ square root of distance from Central Kumasi

$\log H=\log$ of distance from the nearest highway

$P_{1970}=$ size of settlement population in 1970

$P_{1984}=$ size of settlement population in 1984

$P_{2000}=$ size of settlement population in 2000

Absolute population growths (G) during the periods 1970-1984, 1984-2000, 2000-2010 and 1970-2010 are predicted by statistical models $1,2,3$, and 4 , respectively. The regression analysis results presented in Table 1 
show the variable coefficients, statistical significance (based on t-tests) of each coefficient and $\mathrm{R}^{2}$ of each of the four models. For instance, Model (4), which predicts absolute growth in settlement population during the period 1970-2010 (G1970-2010) is specified in the following equation:

$$
G_{1970-2010}=-13,333 \sqrt{C}-2,370 \log H+2 P_{1970}+20,072
$$

As expected, regression models 1 and 3 show a negative and highly significant correlation between the square root of distance from Central Kumasi and population growth. Although model 2 (which predicts population growth during the 1984-2000 inter-censal period) shows a positive correlation, model 4 (which predicts overall population growth between 1970 and 2010) confirms that there is a negative correlation between the square root of distance from Central Kumasi and population growth (see Table 1). That is, after controlling for the effects of base year population size, settlements close to Central Kumasi grew faster than those located farther away. Similarly, all the four models show a negative correlation between the log of distance from highways and population growth, although this relationship was found to be only $90 \%$ significant during the 1970-1984 and 2000-2010 inter-censal periods. That is, after controlling for the effects of base year population, settlements close to highways grew faster than those located farther away. Another interesting finding is that the R-square, which shows the proportion of spatial variation in population growth explained by each model, has increased over time. For instance, while model 1 explained only $16 \%$ of spatial variation in population growth in 1970-1984, model 3 explained $40 \%$ of spatial variation in population growth in 2000-2010. In the case of the 1970-2010 inter-censal period, model 4 explained as much as $42 \%$ of the spatial variation in population growth (see Table 1). This means that the influence of proximity to Central Kumasi and highways on settlement population growth has been increasing over time.

Table 1. Regression coefficients of independent variables and R-squares of models 1, 2, 3 and 4

\begin{tabular}{lrrrr}
\hline $\begin{array}{l}\text { Independent } \\
\text { Variables }\end{array}$ & $\begin{array}{r}\text { Model 1 } \\
\mathbf{( 1 9 7 0 - 1 9 8 4 )}\end{array}$ & $\begin{array}{r}\text { Model 2 } \\
\mathbf{( 1 9 8 4 - 2 0 0 0 )}\end{array}$ & $\begin{array}{r}\text { Model 3 } \\
\mathbf{( 2 0 0 0 - 2 0 1 0 )}\end{array}$ & $\begin{array}{r}\text { Model 4 } \\
\mathbf{( 1 9 7 0 - 2 0 1 0 )}\end{array}$ \\
\hline$\sqrt{ } \mathrm{C}$ & $-3256.379 * * *$ & $4423.787^{* * *}$ & $-13969.230^{* * *}$ & $-13333.410^{* * *}$ \\
$\log \mathrm{H}$ & $-187.39^{*}$ & $-1512.254^{* * *}$ & $-116.879^{*}$ & $-2369.868^{* * *}$ \\
$\mathrm{P}_{1970}$ & $0.165^{* * *}$ & & & $2.001^{* * *}$ \\
$\mathrm{P}_{1984}$ & & & & \\
$\mathrm{P}_{2000}$ & & $0.765^{* * *}$ & & \\
Constant & & & $0.265^{* * *}$ & \\
$\mathrm{R}^{2}$ & $4263.844^{* * *}$ & $-2348.134^{*}$ & $16550.170^{* * *}$ & $20072.210^{* * *}$ \\
No. of observations & 0.1556 & 0.3530 & 0.4083 & 0.4245 \\
\hline $\mathrm{Signi}$ & 406 & 406 & 406 & 406 \\
\hline
\end{tabular}

Significance test: $* \mathrm{P}<0.1 * * \mathrm{P}<0.05 * * * \mathrm{P}<0.01$

\section{Discussion}

The data and modelling techniques used in this paper have revealed that the form and growth of the Greater Kumasi Metropolitan Area follow clear patterns and that these patterns can be explained by existing spatial models that have often been applied to metropolitan areas in Europe, North America and elsewhere. As clearly demonstrated, GKMA exhibits both monocentric and ribbon development patterns of spatial growth. As the monocentric city model suggests, there is a non-linear, negative relationship between distance from Central Kumasi and various variables, including population density and population growth (see Brueckner, 1987; Kraus, 2003; McMillen, 2006; Romein et al., 2009). The negatively sloping population growth and density curves depicted by the data are the result of the fact that proximity to Central Kumasi matters to commuters and businesses. This is in turn due to the socio-economic dominance of the Kumasi Metropolis, particularly Central Kumasi, and the absence of strong sub-centres to compete with the city. In other words, there is a high tendency for residents and economic activities to locate as close to Central Kumasi as possible. Consequently, the most valuable lands are those within or close to Central Kumasi. However, because competition between resident population and economic activities for land is most intense in communities within and around Central Kumasi, the capacity of such communities to absorb additional population will be increasingly constrained over time. 
Thus, in the long term, communities that are farther away from Central Kumasi will register faster growth than those close to it.

The ribbon development pattern exhibited by GKMA is attributed to the fact that most residents in the metropolitan area need to commute to Central Kumasi for jobs, services and for other purposes at the least travel time and cost. However, secondary and access roads needed to provide alternative connections between the city centre and other parts of the metropolitan area are either non-existent or in bad shape. Therefore, it is only rational for commuters to live as close to the main highways as possible, thus creating the ribbon development pattern observed in GKMA (see Chin, 2002; Harvey \& Clark, 1965; Kraus, 2003). This explains why, according to our estimates, $90.5 \%$ of the population of GKMA lived within 4 kilometres of a highway as of 2010 . This phenomenon has also been observed in other African metropolitan areas (see Briggs \& Mwamfupe, 2000; Doan \& Oduro, 2012; Grant \& Yankson, 2003; Mabogunje, 1990). For example, Doan \& Oduro (2012) found that, as of 2000 , about $90 \%$ of the population of peri-urban Accra lived within 4 kilometres of a highway, which is very similar to what we found in GKMA.

The monocentric and ribbon development patterns exhibited by GKMA have serious implications for urban traffic management. As Solow (1972) has demonstrated, transportation (commuting) cost is not only a function of distance from the city centre (CBD) but also a function of traffic congestion cost, which can be measured as the time it takes to cover a unit distance. In turn, congestion is a function of population (residential) density, which has been shown in this and other studies to be negatively related to distance from the centre (CBD) of a monocentric urban area. Therefore, by extension, traffic congestion is negatively related to distance from the centre (CBD) of a monocentric urban area. This explains why in the GKMA and in most metropolitan areas in Africa and elsewhere traffic congestion gets increasingly worse as one approaches the city from the outskirts, especially during the morning and evening rush hours. In the case of GKMA, and most arguably many metropolitan areas in Africa, where monocentricity is combined with ribbon development, traffic congestion is aggravated by the fact that direct access to the city centre is restricted to a handful of radial highways. In other words, the over-reliance on a single dominant centre (i.e. the existence of moncentricity) and the fact that access to the centre is restricted to a few routes imposes huge congestion costs on commuters with serious implications for productivity. The congestion situation is worsened by the absence of an efficient mass transit system and the increasing use of low-capacity vehicles for commercial and non-commercial transport (see Adarkwa \& Poku-Boansi, 2011). This calls for three urban planning interventions. The first is the creation and development of viable and strategically sited sub-centres to reduce the dominance of the main centre. The second is the development of intra-metropolitan connectivity. This will include the development of sufficient radial roads (other than the main highways) connecting the main centre to the sub-centres and other parts of the metropolitan area, as well as the development of circumferential routes (i.e. ring roads) and roads connecting the sub-centres to one another. Thirdly, an efficient mass transit system, which relies on high-capacity vehicles like buses and commuter trains, should be introduced.

Another important finding is that the population of GKMA has grown faster than the rate of expansion of its built-up area. This is contrary to the recent trend in most urban areas in both developed and developing countries where the amount of land (built-up areas) taken up by cities and metropolitan areas is increasing at a faster rate than the rate of population growth (Oduro, 2010). For instance, while the population of Greater Accra Metropolitan Area (GAMA) increased 1.9 times between 1985 and 2002, its built-up area increased 2.6 times (Yankson, Kofie \& Moller-Jensen, 2004). The Kumasi exception may be attributed to urban consolidation through in-fill development in the existing built-up areas, particularly the Kumasi Metropolis. For example, the proportion of the city's land area classified as 'undeveloped' declined from $25 \%$ in 1995 to $18 \%$ in 2010 (Afrane \& Amoako, 2011). While urban consolidation could be a positive development if well-planned, it needs to be emphasised that, in the case of Kumasi, this has been largely unplanned and uncontrolled. As a result, there have been extensive encroachments on open spaces, wetlands, waterways and other lands that are not suitable for residential and commercial developments (see Quagraine, 2011). It is also important to emphasize that the spill-over effects of Kumasi, which have come about through peri-urbanization, are already being felt in the adjoining municipalities. (The term peri-urbanization is used here to refer to the process by which rural settlements, farmlands and other natural areas located on the fringes of a city undergo various physical, economic and social transformations as they get engulfed by the city and thus become urban in character over time (see Oduro, 2010; Simon et al., 2004; Webster \& Muller, 2002)). Some of the effects include: the conversion of prime farmlands to residential and other urban developments; low-density and leapfrog developments associated with sprawl; the pollution of the atmosphere, water bodies and soils resulting from urban activities; and land degradation through the quarrying of sand and stones to feed the city's construction 
industry (see Aberra \& King, 2005; Afrane \& Amoako, 2011; Simon et al., 2004). To halt or minimize these adverse effects of urban growth, there is the urgent need for the various local government authorities to adopt and vigorously enforce a joint urban planning system that is metropolitan-wide in approach and long-term in perspective.

\section{Conclusion}

Rapid urbanization over the decades has created metropolitan regions and other complex urban systems in many countries, including African countries. Although such urban systems serve as the engines of economic growth and social transformations, they are associated with myriad problems that sometimes overwhelm local governments. Kumasi, the second largest city in Ghana, has grown rapidly during the last four decades resulting in the expansion of the city's built-up area, conversion of farmlands to urban uses and the intensification of spatial interactions between the city and settlements in neighbouring municipalities. To effectively manage the growth of African cities, there is the need to deepen our understanding of the nature and pattern of growth of these cities and the urban spatial structure and form they produce. In this study, we sought to determine the patterns of growth of GKMA using spatial and statistical modelling techniques.

The paper has revealed that the form and growth of GKMA follow discernible patterns that can be explained by existing spatial models. We found that GKMA exhibits both monocentric and ribbon development patterns of spatial growth. These patterns of growth, which are influenced by the over-reliance on a single dominant centre and restriction of access to the centre to a few radial routes, have contributed to traffic congestion. In addition, the growth of the built-up area, which has been largely unplanned and uncontrolled, has resulted in encroachments on open spaces, wetlands and waterways in the city, as well as the conversion of prime farmlands into urban developments, sprawl, and negative environmental impacts in the peri-urban areas. We therefore recommend the following: the creation and development of sub-centres to reduce the dominance of Central Kumasi; the development of more radial and circumferential routes (including ring roads); introduction of an efficient mass transit system; and the adoption and vigorous enforcement of an urban planning system that is metropolitan-wide in approach and long-term in perspective.

\section{References}

Aberra, E., \& King, R. (2005). Additional knowledge of livelihoods in the Kumasi peri-urban interface, Ashanti Region, Ghana. A project report (Boafo Ye Na project) for Development Planning Unit (DPU), University College London, London, UK. Retrieved from http://www.nrsp.org.uk/database/documents/2813.pdf

Adarkwa, K. K., \& Poku-Boansi, M. (2011). Rising vehicle ownership, roadway challenges and traffic congestion in Kumasi. In K. K. Adarkwa (Ed), Future of the tree: Towards growth and development of Kumasi (pp. 128-152). Kumasi: University Printing Press (UPK).

Afrane, S., \& Amoako, C. (2011). Peri-urban development in Kumasi. In K. K. Adarkwa (Ed), Future of the tree: Towards growth and development of Kumasi (pp. 92-110). Kumasi: University Printing Press (UPK).

Ajala1, O. A., \& Olayiwola, A. M. (2013). An assessment of the growth of Ile-Ife, Osun State, Nigeria, using multi-temporal imageries. Journal of Geography and Geology, 5(2), 43-54. http://dx.doi.org/10.5539/jgg.v5n2p43

Alonso, W. (1964). Location and land use: Toward a general theory of land. Cambridge: Harvard University Press. http://dx.doi.org/10.4159/harvard.9780674730854

Alonso-Villar, O. (2001). Large metropolises in the Third World: An explanation. Urban Studies, 38(8), 1359-1371. http://dx.doi.org/10.1080/00420980120061070

Anas, A., Arnott, R., \& Small, K. A. (1998). Urban spatial structure. Journal of Economic Literature, 36(3), 1426-1464.

Retrieved

from http://www.jstor.org/discover/10.2307/2564805?uid=2\&uid=4\&sid=21103542657933

Anderson, W. P., Kanaroglou, P. S., \& Miller, E. J. (1996). Urban form, energy and the environment: A review of issues, evidence and policy. Urban Studies, 33(1), 7-35. http://dx.doi.org/10.1080/00420989650012095

Bairoch, P. (1988). Cities and economic development: From the dawn of history to the present (translated by Christopher Braider). Chicago: University of Chicago Press.

Bertinelli, L., \& Black, D. (2004). Urbanization and growth. Journal of Urban Economics, 56(1), 80-96. http://dx.doi.org/10.1016/j.jue.2004.03.003 
Boshoff, D. G. B., \& Marais, D. (2013). The effects of the expanding outskirts of Tshwane on its CBD and internal structure. Proceedings in Advanced Research in Scientific Areas (ARSA), Volume 2 Issue 1. Retrieved from http://www.arsa-conf.com/archive/?vid=1\&aid=3\&kid=60201-84\&q=f6

Briggs, J., \& Mwamfupe, D. (2000). Peri-urban development in an era of structural adjustment in Africa: The city of Dar es Salaam, Tanzania. Urban Studies, 37(4), 797-809. Retrieved from http://urbanlandmark.org.za/downloads/Peri-urban\%20Development_Dar_es_Salaam.pdf

Brueckner, J. K. (1987). The structure of urban equilibria: A unified treatment of the Muth-Mills model. In E. S. Mills (Ed), Handbook of regional and urban economics volume 2 (pp. 821-845). North-Holland, Amsterdam

Chin, N. (2002). Unearthing the roots of urban sprawl: A critical analysis of form, function and methodology. Paper 47, CASA Working Paper Series, University College London, London, UK. Retrieved from http://eprints.ucl.ac.uk/249/1/Paper47.pdf

Chirisa, I. (2008). Population growth and rapid urbanization in Africa: Implications for sustainability. Journal of Sustainable Development in Africa, 10(2), 361-394. Retrieved from http://hdl.handle.net/10646/587

Clark, C. (1951). Urban Population Densities. Journal of the Royal Statistical Society, Series A (General), 114(4), 490-496. Retrieved from ftp://ftp.ecn.purdue.edu/jshan/upload200702/Alkheder/sharaf_afterdefense/research/PHDwork_nov_2005/p opulation.pdf

Cobbinah, P. B., \& Amoako, C. (2012). Urban sprawl and the loss of peri-urban land in Kumasi, Ghana. International Journal of Social and Human Sciences, 6, 388-397. Retrieved from http://www.researchgate.net/publication/232957200_Urban_Sprawl_and_the_Loss_of_Peri_Urban_Land_i n_Kumasi_Ghana

Dickinson, H. D. (1969). Von Thünen's economics. The Economic Journal, 79(316), 894-902. Retrieved from http://links.jstor.org/sici?sici=0013-0133\%28196912\%2979\%3A316\%3C894\%3AVTE\%3E2.0.CO\%3B2M\&origin $=\mathrm{bc}$

Doan, P., \& Oduro, C. Y. (2012). Patterns of population growth in peri-urban Accra, Ghana. International Journal of Urban and Regional Research, 36(6), 1306-1325. http://dx.doi.org/10.1111/j.1468-2427.2011.01075.x

Ghana Statistical Service. (2012). 2010 Population and housing census: Summary report of final results. Accra: Ghana Statistical Service.

Glaeser E. L. (1999). Learning in cities. Journal of Urban Economics, 46, 254-277. http://dx.doi.org/10.1006/juec.1998.2121

Grant, R., \& Yankson, P. (2003). City profile: Accra. Cities, 20(1), 65-74. http://dx.doi.org/10.1016/S0264-2751(02)00090-2

Hall, P. (1997). Modelling the post-industrial city. Futures, 29(4/5), 311-322. http://dx.doi.org/10.1016/S0016-3287(97)00013-X

Harvey, E. O., \& Clark W. (1965). The nature and economics of urban sprawl. Land Economics, 41(1), 1-9. Retrieved from http://www.jstor.org/stable/3144884

Henderson, V. (2002). Urbanization in developing countries. The World Bank research observer, 17(1), 89-112. http://dx.doi.org/10.1093/wbro/17.1.89

Henderson, V. (2004). Urbanization and growth. In P. Aghion, \& S. Durlauf (Eds.), Handbook of economic growth (Vol. 1, pp. 1543-1591). San Diego: Elsevier Inc.

Kahimbaara, J. A. (1986). The population density gradient and the spatial structure of a Third World city: Nairobi, A Case Study. Urban Studies, 23(4), 307-322. http://dx.doi.org/10.1080/00420988620080361

Kraus, M. (2003). Monocentric cities. A working paper in Economics, Economics Department, Boston College, Boston, MA, USA. Retrieved from http://escholarship.bc.edu/econ papers/64

Krugman, P. (1991). Increasing returns and economic geography. Journal of Political Economy, 99(3), 483-499. Retrieved from http://www.princeton.edu/pr/pictures/g-k/krugman/krugman-increasing_returns_1991.pdf

Linard, C., Tatem, A. J., \& Gilbert, M. (2013). Modelling spatial patterns of urban growth in Africa. Applied Geography, 44, 23-32. http://dx.doi.org/10.1016/j.apgeog.2013.07.009 
Mabogunje, A. (1990). Urban planning and the post-colonial state in Africa: A research overview. African Studies Review, 33(2), 121-203. Retrieved from http://www.jstor.org/stable/524471

McMillen, D. P. (2006). Testing for monocentricity. In A. Richard, \& D. McMillen (Eds.), A Companion to urban economics. Malden, MA: Blackwell Publishing Ltd. http://dx.doi.org/10.1002/9780470996225.ch8

Moomaw, R. L. (1996). Urbanization and economic development: a bias toward large cities? Journal of Urban Economics, 40, 13-37. http://dx.doi.org/10.1006/juec.1996.0021

Oduro, C. Y. (2010). Effects of rapid urbanization on livelihoods in the peri-urban areas of Accra, Ghana (Doctoral dissertation). Florida State University, Tallahassee, FL, USA. Available from Diginole Commons: Electronic theses, treatises and dissertations. Paper 7207. http://diginole.lib.fsu.edu/etd/7207

Potter, R. B., \& Lloyd-Evans, S. (1998). The City in the Developing World. London: Pearson.

Quagraine, V. K. (2011). Urban landscape depletion in the Kumasi metropolis. In K. K. Adarkwa (Ed), Future of the tree: Towards growth and development of Kumasi (pp. 212-233). Kumasi: University Printing Press (UPK).

Romein, A., Verkoren, O., \& Fernandez-Maldonado, A. (2009). Polycentric metropolitan form: application of a 'Northern' concept in Latin America. Footprint: Metropolitan Form, (5), 127-128. Retrieved from http://dspace.library.uu.nl/handle/1874/289110

Simon, D., McGregor, D., \& Nsiah-Gyabaah, K. (2004). The changing urban-rural interface of African cities: Definitional issues and an application to Kumasi, Ghana. Environment and Urbanization, 16(2), 235-247. http://dx.doi.org/10.1177/095624780401600214

Solow, R. M. (1972). Congestion, density and the use of land in transportation. Swedish Journal of Economics, 74(1), 161-173. http://dx.doi.org/10.2307/3439015

Torrens, P. M. (2000). How land-use-transportation models work. Paper 20, Centre for Advanced Spatial Analysis (CASA) Working Paper Series. University College London, London, UK. Retrieved from http://discovery.ucl.ac.uk/1365/1/paper20.pdf

Trussell, B. (2010). Bid rent gradient theory in Eugene, Oregon: An empirical investigation. Department of Economics, University of Oregon. Retrieved http://economics.uoregon.edu/honors-papers/2010/BenjaminTrussell.pdf

Uju, I. V. \& Iyanda, S. T. (2012). Comparative analysis of the determinants of residential land values. Chinese Business Review, 11(2), 187-192.

UN (2012). World urbanization prospects: The 2011 revision. New York: Department of Economic and Social Affairs, Population Division, UN.

UN-Habitat. (2008). State of the world cities 2010/2011: Bridging the urban divide. Earthscan, UK and USA.

Vermeiren, K., Van Rompaey, A., Loopmans, M., Serwajja, E., \& Mukwaya, P. (2012). Urban growth of Kampala, Uganda: Pattern analysis and scenario development. Landscape And Urban Planning, 106(2), 199-206. http://dx.doi.org/10.1016/j.landurbplan.2012.03.006

Webster, D., \& Muller, L. (2002). Challenges of peri-urbanization in the Lower Yangtze Region: The case of the Hangzhou-Ningbo Corridor. A paper for the Asia/ Pacific Research Center, Stanford University. Retrieved from http://iis-db.stanford.edu/pubs/20029/Webster-Muller.pdf

World Bank. (2000). World development report 1999-2000: Entering the 21st century. New York: Oxford University Press.

Yankson, P. W. K., Kofie, R. Y., \& Moller-Jensen, L. (2005). Monitoring urban growth: Urbanization of the fringe areas of Accra. Bulletin of Ghana Geographical Association, No.24, 1-13.

\section{Copyrights}

Copyright for this article is retained by the author(s), with first publication rights granted to the journal.

This is an open-access article distributed under the terms and conditions of the Creative Commons Attribution license (http://creativecommons.org/licenses/by/3.0/). 